\title{
COMPOSIÇÃO FLORÍSTICA E POTENCIAL DE REGENERAÇÃO DA MATA CILIAR REMA- NESCENTE DE UM TRIBUTÁRIO DO VACACAÍ-MIRIM, SANTA MARIA - RS
}

\author{
THE FLORISTIC COMPOSITION AND THE REGENERATION POTENTIAL OF THE REMAINING \\ RIPARIAN FOREST OF A VACACAÍ-MIRIM RIVER TRIBUTARY
}

\author{
Denise Ester Ceconi ${ }^{1}$ Igor Poletto $^{2}$ Simone Martini Salvador ${ }^{3}$ Daniel Gustavo Allasia Piccilli ${ }^{4}$
}

\begin{abstract}
RESUMO
O presente trabalho teve como objetivo avaliar a composição florística da mata ciliar remanescente da Sanga Lagoão do Ouro, procurando obter informações acerca de sua degradação, analisando a distribuição das espécies nos diferentes estratos florísticos, a regeneração natural e a presença de espécies exóticas. O estudo foi realizado na mata ciliar da Sanga Lagoão do Ouro, tributário de $3^{\mathrm{a}}$ ordem do Vacacaí-mirim. Sua nascente localiza-se em área urbana, percorrendo várias vilas, o Campus da UFSM, além de uma extensa área rural. Os solos predominantes classificam-se como: Argissolos Bruno-Acinzentados, Vermelho-Amarelos e Vermelhos, além de Planossolos Háplicos, sendo estes de baixa fertilidade natural e bastante suscetíveis à erosão hídrica. O levantamento florístico ocorreu em 12 parcelas de $300 \mathrm{~m}^{2}$ cada, demarcadas ao longo da margem da Sanga Lagoão do Ouro, em que foram avaliados os estratos: plântulas, regeneração natural e arbóreo. O levantamento florístico mostrou haver degradação da mata ciliar, evidenciada pelo baixo número de espécies nativas, pela má distribuição das espécies nos diferentes estratos e pela grande presença de espécies exóticas. Possuem maior potencial de regeneração natural nas espécies que apresentaram maior frequência e que aparecem nos três estratos florísticos levantados, tais como: Eugenia uniflora, Allophylus edulis (A.St.-Hil., Cambess. \& A. Juss.) Radlk, Psidium guajava L., Cestrum strigilatum Ruiz \& Pav., Prunus myrtifolia (L.) Urb., Zanthoxylum rhoifolium Lam., Casearia sylvestris Sw., Cupania vernalis Cambess. e Schinus terebinthifolius Raddi.
\end{abstract}

Palavras-chave: degradação; ecossistema ciliar; regeneração natural.

\begin{abstract}
This work aimed to evaluate the floristic composition of the remaining riparian forest of a stream called 'Sanga Lagoão do Ouro', seeking to obtain information about its degradation, analyzing the distribution of the species in the different floristic strata, the natural regeneration and the exotic species presence. The study was conducted at the riparian forest of 'Sanga Lagoão do Ouro', which is tributary of the third order of 'Vacacaí-mirim' River. Its spring is located in an urban area, covering several villages, the campus of Federal University of Santa Maria as well as an extensive rural area. The predominant soils are classified as: Bruno-Grayish (Bruno-Acinzentados), Red-Yellow (Vermelho-Amarelos) and Red (Vermelhos) Alfisols (Argissolos) and Udalf soil (Planossolos Háplicos), which are of low natural fertility and quite susceptible to water erosion. The floristic surveying was accomplished in 12 sampling plots of $300 \mathrm{~m}^{2}$ each, demarcated along the margin of the stream where the strata were evaluated: seedlings, natural regeneration and arbo-

1 Engenheira Florestal, Dra ${ }^{\mathrm{a}}$, Pós-doutoranda do Programa de Pós-Graduação em Engenharia Ambiental, Centro de Tecnologia, Universidade Federal de Santa Maria, Av. Roraima, 1000, Prédio 10, Sala 522, CEP 97105-900, Santa Maria (RS), Brasil. deniceconi@gmail.com

2 Engenheiro Florestal, Dr., Professor da Universidade Federal do Pampa, Av. Antônio Trilha, 1847, CEP 97300000, São Gabriel (RS), Brasil. poletto.unipampa@gmail.com

3 Engenheira Florestal, MSc., Av. Luiz Amadeo Lodi, 1161, complemento 09, Centro, CEP 78890-000, Sorriso (MT), Brasil. simone.ufsm@gmail.com

4 Engenheiro Civil, Dr., Professor do Departamento de Engenharia Sanitária e Ambiental, Centro de Tecnologia, Universidade Federal de Santa Maria, Av. Roraima, 1000, Prédio 10, Sala 533, CEP 97105-900, Santa Maria (RS), Brasil. dallasia@gmail.com
\end{abstract}

Recebido para publicação em 8/11/2010 e aceito em 24/01/2018

Ci. F1., v. 28, n. 4, out. - dez., 2018 
real. The floristic survey shows degradation of the studied riparian forest, which is evidenced by the low number of native species, the poor distribution of the species in the different strata and the great presence of exotic species. The species that present the highest frequency and which appear in the three floristic strata mentioned in this study have greater for natural regeneration, such as: Eugenia uniflora, Allophylus edulis, Psidium guajava, Cestrum strigilatum, Prunus myrtifolia, Zanthoxylum rhoifolium, Casearia sylvestris, Cupania vernalis and Schinus terebinthifolius.

Keywords: degradation; riparian ecosystem; natural regeneration.

\section{INTRODUÇÃO}

As matas ciliares fazem parte da paisagem adjacente a um curso d'água e desempenham importantes funções como proteger o solo das margens dos rios, impedindo o aporte de sedimentos ao leito, melhorando a qualidade da bacia hidrográfica, além de formarem corredores ecológicos (VOGEL; ZAWADZK; METRI, 2009; CALLEGARO et al., 2012b). Outra importante função das matas ciliares é diminuir significativamente a concentração de herbicidas e fertilizantes nos cursos d'água de bacias tratadas com tais produtos (CARPANEZZI, 2000), conservando, assim, a quantidade e a qualidade da água. Isto faz com que estes locais sejam protegidos por lei, constituindo-se em áreas de preservação permanente da flora e fauna (RACHWAL; CAMATI, 2001).

No entanto, o que se observa é a degradação das matas ciliares, inclusive as pertencentes à Floresta Estacional Decidual, sendo que os remanescentes deste tipo florestal se apresentam fragmentados, formando florestas secundárias em diferentes estágios de sucessão. A Floresta Estacional Decidual abrange mais de um milhão de hectares e corresponde a $23,8 \%$ das florestas do RS, constituindo a mais extensa formação fitogeográfica do Estado (RIO GRANDE DO SUL, 2002). No Rebordo do Planalto Meridional, as áreas de encosta e as matas ciliares retêm boa parte dos fragmentos de Floresta Estacional, apresentando variação florística e estrutural conforme cada ambiente (CALLEGARO et al., 2012a).

A Lei de Proteção da Vegetação Nativa (Lei no 12.651, de 25 de maio de 2012) estabelece limites rígidos de largura para as faixas de vegetação marginal de cursos d'água, baseados na largura dos corpos d'água e no tamanho da propriedade, ou seja, no número de módulos fiscais (BRASIL, 2012), mas não apresenta critérios científicos para determinação de largura das áreas ciliares. Bren (1993) já reportava a não existência de um método definitivo para estabelecimento da largura mínima da faixa ciliar na zona ripária, que possibilite uma proteção satisfatória do curso d'água.

A fragmentação das matas ciliares limita à manutenção da biodiversidade. Muitas espécies de animais e de árvores exigem áreas grandes para perpetuar-se, isto ressalta a importância de que as matas ciliares sejam restauradas o quanto possível, e que sejam interligadas. Além de constituir um habitat para a fauna e a flora terrestres, a mata ciliar bem conservada tem efeitos importantes sobre plantas e animais dos corpos d'água adjacentes, pois seus frutos e sementes são fontes de alimento para a fauna e de propágulos para a flora (RACHWAL; CAMATI, 2001).

O Novo Código Florestal Brasileiro (Lei $\mathrm{n}^{\circ}$ 12.651, de 25 de maio de 2012) inclui às áreas de preservação permanente, as faixas marginais dos corpos d'água cobertas ou não por vegetação nativa, com a função ambiental de preservar os recursos hídricos, a paisagem, a estabilidade geológica, a biodiversidade, o fluxo gênico da fauna e flora, proteger o solo e assegurar o bem estar das populações (BRASIL, 2012).

Apesar da preservação das matas ciliares estar prevista em lei, estas, continuamente, estão sendo eliminadas. Sua degradação não pode ser discutida sem considerar a sua inserção no contexto do uso e da ocupação do solo, sendo o resultado da expansão desordenada das fronteiras agrícolas (MARTINS, 2001). Esta expansão tem se caracterizado pela inexistência ou ineficiência de um planejamento ambiental prévio, que possibilita delimitar as áreas que poderiam ser efetivamente ocupadas pelas atividades agropecuárias e as áreas que deveriam ser preservadas em função de suas características ambientais ou mesmo legais.

A forma mais frequente de degradação de ecossistemas naturais pelo ser humano tem sido a destruição das florestas para a extração de madeira e a abertura de espaços para as suas atividades agrícolas, expansão da silvicultura intensiva, pecuária, produção de matéria-prima para agroenergia, expansão de áreas industriais e de desenvolvimento urbano (SHIMIZU, 2007). 
A recuperação de áreas degradadas é, portanto, uma consequência do uso incorreto da paisagem e fundamentalmente dos solos, sendo apenas uma tentativa limitada de remediar um dano que na maioria das vezes poderia ter sido evitado. O próprio desenvolvimento de estratégias mais coerentes e eficientes para a recuperação de áreas degradadas não deve respaldar a manutenção ou expansão deste processo contínuo de degradação. É necessário também, que as autoridades responsáveis pela conservação ambiental adotem uma postura rígida no sentido de preservar as florestas ciliares que ainda restam, e que os produtores rurais e a população em geral sejam sensibilizados sobre a importância da conservação desta vegetação.

Neste sentido, a análise de matas ciliares com área reduzida é necessária, pois essas matas tendem a apresentar uma dinâmica sucessional e uma estrutura diferente das observadas em formações florestais de áreas extensas e em estágios mais avançados de desenvolvimento.

$\mathrm{Na}$ região do presente estudo, na qual se inclui o município de Santa Maria, as formações florestais de tamanho reduzido normalmente não são pesquisadas, devido, em parte, às alterações e à área reduzida dessas florestas. No entanto, fica evidente a importância de formações como as matas ciliares, pois englobam parte da biodiversidade da Floresta Estacional do Rio Grande do Sul, auxiliando na conservação da fauna e da flora regional (CALLEGARO et al., 2012a).

O presente trabalho teve como objetivo avaliar a composição florística da mata ciliar remanescente da Sanga Lagoão do Ouro na microbacia hidrográfica do Vacacaí-mirim, Santa Maria-RS, procurando obter informações acerca de sua degradação, analisando a distribuição das espécies nos diferentes estratos florísticos, a regeneração natural e a presença de espécies exóticas.

\section{MATERIAL E MÉTODOS}

\section{Descrição da área de estudo}

O presente estudo foi realizado nas margens da Sanga Lagoão do Ouro, tributário de $3^{\mathrm{a}}$ ordem do Rio Vacacaí-mirim, que está localizada na microbacia hidrográfica do Vacacaí-mirim, no município de Santa Maria-RS (coordenadas $29^{\circ} 45^{\prime}$ S e $53^{\circ} 43^{\prime}$ W). A nascente da Sanga localiza-se no Residencial Novo Horizonte, percorrendo o Núcleo Habitacional Fernando Ferrari, Vila Santos Dumont, Vila Santa Tereza, Vila Assunção e o Campus da UFSM, além de uma extensa área em zona rural, até desaguar no rio Vacacaí-mirim.

O relevo apresenta-se suavemente ondulado, caracterizado pela presença de coxilhas e planícies aluviais, com cotas altimétricas variando de 40 a 200 metros, caracterizando uma paisagem sem grande variação de altitude (SPIAZZI, 2002).

O clima da bacia segundo a classificação climática de Köppen, é do tipo Cfa, caracterizado como subtropical, em que a temperatura do mês mais frio oscila entre $-3^{\circ} \mathrm{C}$ e $18^{\circ} \mathrm{C}$, a média do mês mais quente ultrapassa $23^{\circ} \mathrm{C}$ e a média anual é de $18,2^{\circ} \mathrm{C}$. A insolação é de 2.300 horas (MORENO, 1961). A precipitação pluviométrica anual é de $1.382 \mathrm{~mm}$, distribuída uniformemente ao longo do ano (COGO; ELTZ; CASSOL, 2006).

Os solos predominantes classificam-se como Argissolo Bruno-Acinzentado, Argissolo Vermelho-Amarelo, Argissolo Vermelho, e Planossolo Háplico. Estes solos são de baixa fertilidade natural e bastante suscetíveis à erosão hídrica (STRECK et al., 2002). Conforme Pedron et al. (2006), os Argissolos Bruno-Acinzentado, antigo Alissolos, na área urbana de Santa Maria correspondem a 44\% e os Argissolos Vermelho-Amarelo e Vermelho correspondem a $25 \%$ dos solos formadores desta, sendo que estes solos apresentam alta suscetibilidade à degradação ambiental quando manejados inadequadamente, principalmente devido à erosão hídrica, pela presença de mudança textural, originando a ocorrência de voçorocas, que tornam estes ambientes de risco a ocupação humana.

O Bairro Camobi, onde nasce o tributário Lagoão do Ouro, é margeado pelo Rio Vacacaí-mirim que integra a Bacia do Rio Jacuí. O Rio Vacacaí-mirim nasce do topo do planalto no município de Itaara, tem como seus principais tributários os Arroios Grande, do Veado, do Meio e Manuel Alves, constituindo-se no rio principal da Região Centro-Leste de Santa Maria, abastecendo a barragem do DNOS, situado ao "pé" do Rebordo do Planalto Meridional. Ao norte, o rio Vacacaí-mirim apresenta uma extensa planície aluvial, 
com cotas altimétricas que se aproximam a 70 m (SPIAZZI, 2002).

\section{Demarcação das parcelas e levantamento florístico}

O levantamento florístico da mata ciliar ocorreu em 12 parcelas amostrais de $10 \mathrm{~m}$ x $30 \mathrm{~m}\left(300 \mathrm{~m}^{2}\right)$, demarcadas ao longo da Sanga Lagoão do Ouro (Figura 1). O dimensionamento das parcelas a campo foi realizado com o uso de balizas e de uma trena, cujos $10 \mathrm{~m}$ foram medidos no sentido paralelo e os $30 \mathrm{~m}$ no sentido perpendicular à Sanga.

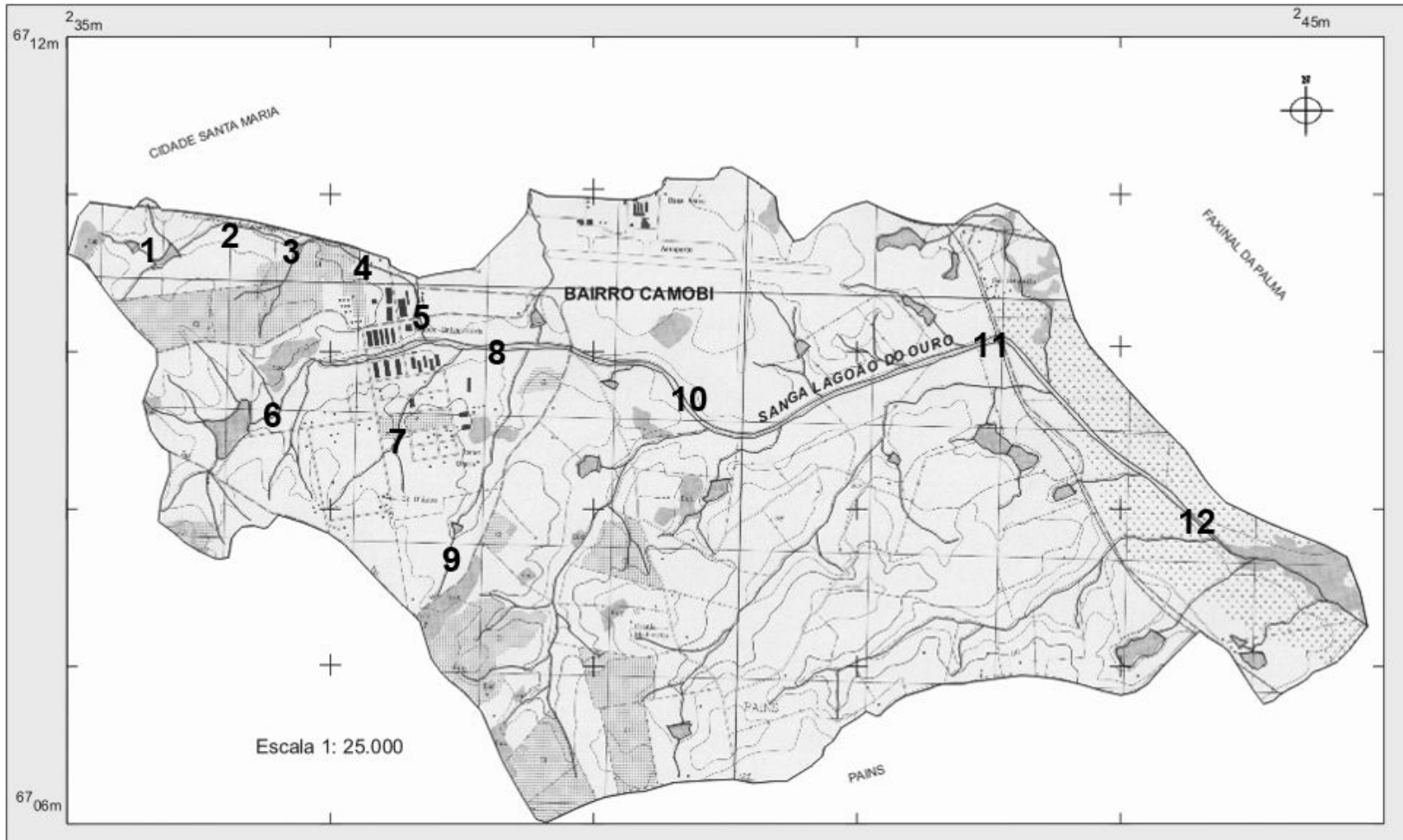

FIGURA 1: Localização da área de estudo e das 12 parcelas amostrais ao longo do percurso da Sanga Lagoão do Ouro, Santa Maria-RS (Fonte: Carta Topográfica de Camobi, 1975. E: 1:25000).

FIGURE 1: Location of the study area and the 12 sampling plots along the course of 'Lagoão do Ouro' stream, Santa Maria-RS state.

As parcelas foram demarcadas aleatoriamente nas ravinas, nos canais e no tributário, para assim levantar toda a variabilidade de espécies que eventualmente possam ocorrer em função da localização na microbacia (altitude) ou da presença constante ou não de água dentro da Sanga, já que as ravinas e os canais não são perenes. No momento da demarcação das parcelas, os $30 \mathrm{~m}$ transversais foram distribuídos de forma sistemática de uma parcela para outra (ora do lado direito ora do lado esquerdo) e subdivididos em $0-5$, 5-10, 10-20 e 20-30 m de distância da margem. Essa forma de demarcação visou auxiliar o levantamento da possível variabilidade de espécies em função da largura da mata ciliar e da distância da margem da Sanga.

No levantamento para identificação da composição florística, as espécies foram classificadas em três estratos assim denominados: plântulas, regeneração natural e arbóreo. $\mathrm{O}$ estrato plântulas foi formado por indivíduos com até $0,30 \mathrm{~m}$ de altura, com nível mínimo de inclusão em torno de $5 \mathrm{~cm}$ e/ou que as plântulas tivessem folhas características da espécie e que permitisse a identificação; o estrato regeneração natural por indivíduos com altura entre $0,30 \mathrm{~m}$ e $1,30 \mathrm{~m}$ e o estrato arbóreo por indivíduos com altura superior a 1,30 m. Avaliaram-se espécies arbóreas nativas e exóticas e as espécies típicas de capoeirão, ou seja, aquelas que iniciam o processo de sucessão florestal após a degradação de uma área.

Para a análise da estrutura horizontal da vegetação considerou-se o parâmetro frequência absoluta e 
relativa e, densidade absoluta e relativa das espécies descritas em Martins (1991). Além disso, foi avaliado o índice de diversidade de Shannon. O reconhecimento das espécies foi realizado in loco. Para os indivíduos não reconhecidos no local, foi coletado material botânico para posterior identificação no Herbário do Departamento de Ciências Florestais da UFSM, no qual, também, foi realizada a classificação, em nível de família e gênero. As espécies foram classificadas pelo sistema de classificação APG IV (ANGIOSPERM PHYLOGENY GROUP, 2016).

\section{RESULTADOS E DISCUSSÃO}

$\mathrm{Na}$ Figura 2, que apresenta o número de espécies acumuladas por área amostrada da mata ciliar da Sanga Lagoão do Ouro, pode-se observar que o incremento do número de espécies acumuladas foi pouco expressivo nos primeiros $900 \mathrm{~m}^{2}$ de área amostrada, devendo-se ao fato destes se localizarem em área urbana, o que levou à degradação da mata ciliar, restando poucas espécies. O meio urbano, por seus impactos mais acentuados sobre os recursos naturais causa, geralmente, degradação de ordem e importância maior e mais intensa se comparado com o meio rural. Em se tratando de urbanização em áreas que margeiam cursos d'água e que deveriam ser de preservação permanente, estes impactos acabam tomando proporções ainda maiores e muitas vezes de difícil remediação, pois, além da vegetação nativa destruída, acabam degradando o solo e a água.

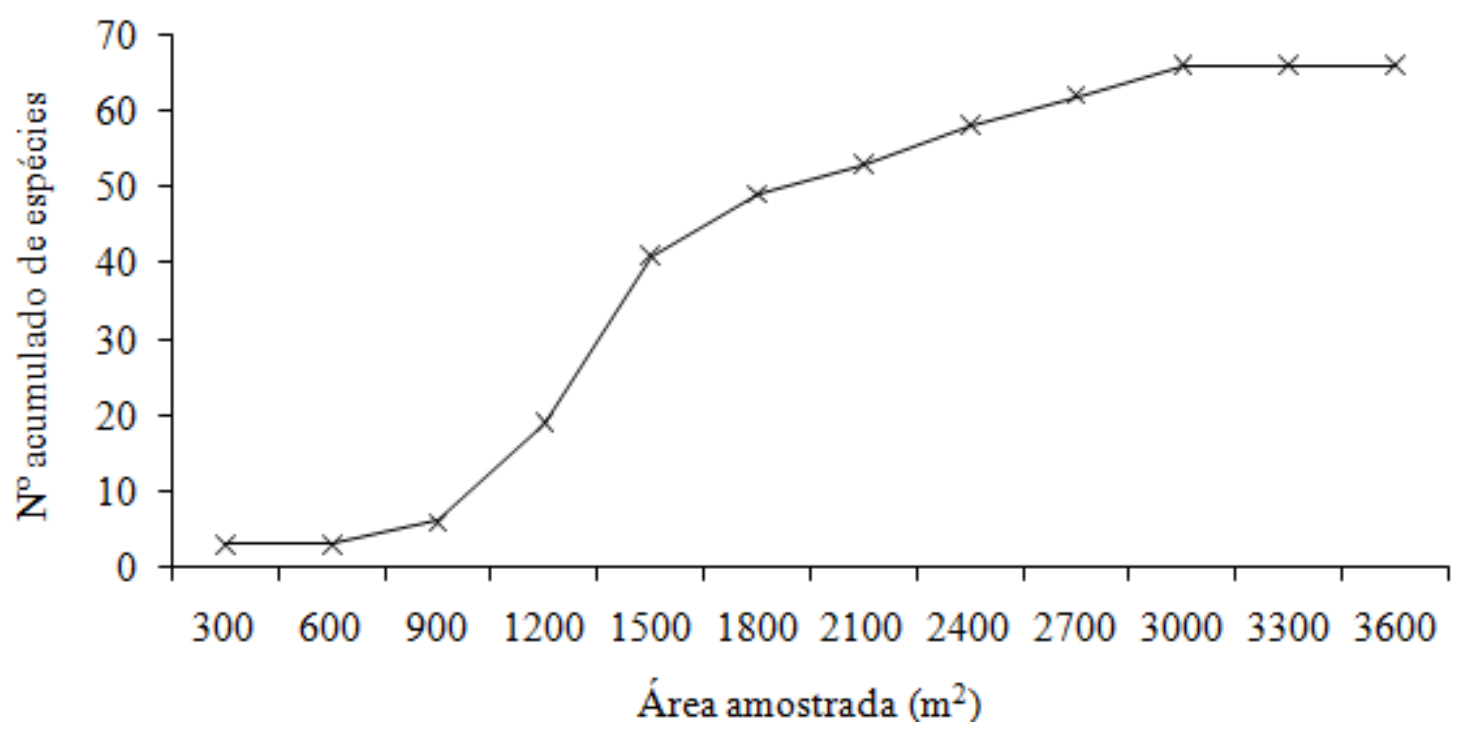

FIGURA 2: Número acumulado de espécies por área amostrada da mata ciliar da Sanga Lagoão do Ouro, Santa Maria-RS.

FIGURE 2: Accumulated number of species for sampling area of the riparian forest of 'Lagoão do Ouro' stream, Santa Maria-RS state.

Além da acentuada degradação da mata ciliar observada nas três primeiras parcelas avaliadas (primeiros $900 \mathrm{~m}^{2}$ de área amostrada), localizadas em área urbana, outras parcelas, localizadas em área rural, apresentaram condições de distribuição semelhante, ou seja, com as poucas espécies que nelas existiam distribuídas de forma esparsa dentro dos limites de $30 \mathrm{~m}$ de largura da parcela amostrada ou então com todas as espécies/indivíduos concentrados junto à margem da Sanga, ou seja, nos primeiros $5 \mathrm{~m}$ a partir do curso d'água. Esta reduzida largura de mata ciliar, muito aquém do que prevê a legislação brasileira, mostra que há um acentuado grau de degradação da mata ciliar da Sanga Lagoão do Ouro.

Um aumento expressivo do número acumulado de espécies foi observado até $1.500 \mathrm{~m}^{2}$ de área amostrada (da parcela quatro a seis), seguido de um incremento menor até a décima parcela $\left(3.000 \mathrm{~m}^{2}\right)$, a partir da qual houve estabilização. No trabalho realizado por Longhi et al. (2000), em fragmentos de Floresta Estacional Decidual, no município de Santa Maria- RS, mesmo tipo florestal do presente estudo, 
estes observaram que houve uma estabilização parcial da curva espécie/área, entre 1.400 e $2.100 \mathrm{~m}^{2}$ da área amostral, no entanto, à medida que foi aumentando a altitude, houve um acréscimo no número de espécies, voltando a se estabilizar em torno dos $2.400 \mathrm{~m}^{2}$. Os resultados observados pelos autores assemelham-se com os do presente estudo, em que a curva estabilizou em $3.000 \mathrm{~m}^{2}$, porém, se forem desconsideradas as três primeiras parcelas avaliadas que se encontravam extremamente degradadas, pode-se afirmar que a curva espécie/área se estabilizou em $2.100 \mathrm{~m}^{2}$.

No levantamento florístico foram observados 4.877 indivíduos, nas 12 parcelas avaliadas $(3.600$ $\mathrm{m}^{2}$ ), sendo que destes, $17,74 \%$ encontram-se no estrato arbóreo, $33,36 \%$ no estrato da regeneração natural e 48,90\% no estrato de plântulas (Figura 3). Esta distribuição nos estratos, em forma de "J invertido", é normal para vegetação arbórea natural, com maior número de indivíduos nos estratos inferiores diminuindo para os estratos superiores de forma balanceada.

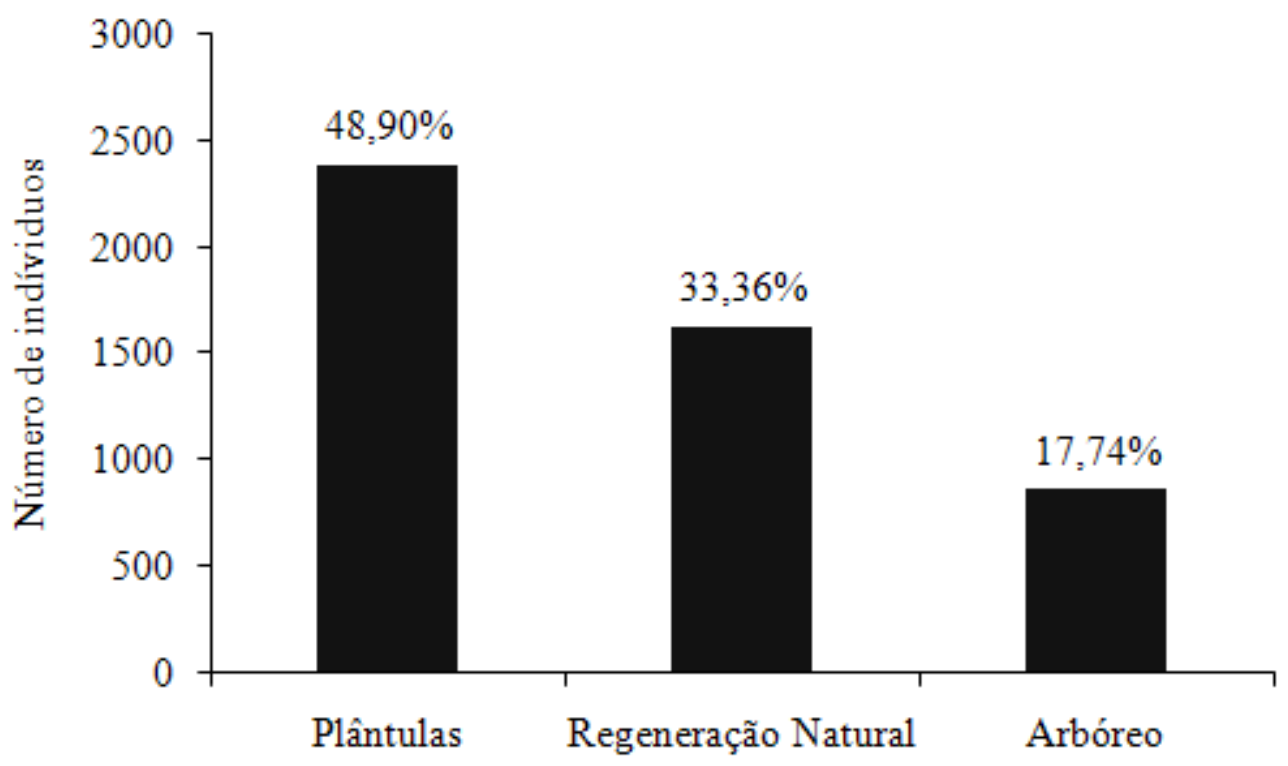

\section{Estratos florísticos}

FIGURA 3: Número de indivíduos amostrados na mata ciliar da Sanga Lagoão do Ouro, Santa Maria-RS, com respectivas porcentagens nos diferentes estratos florísticos.

FIGURE 3: Number of sampling individuals in the riparian forest of 'Lagoão do Ouro' stream, Santa Maria-RS state, with the respective percentages in the different floristic strata.

Foram observadas 66 espécies no total do levantamento florístico, distribuídos em 32 famílias botânicas e 59 gêneros (Tabela 1). Destas, apenas 39 foram encontradas nos três estratos, sendo que no estrato de plântulas estavam presentes 49 espécies, no estrato de regeneração natural 55 e no estrato arbóreo também 55

TABELA 1: Espécies encontradas no levantamento florístico (estratos arbóreo, regeneração natural e plântulas) realizado na Sanga Lagoão do Ouro, Santa Maria-RS.

TABBLE 1: Species found in the floristic survey (arboreal strata, natural regeneration and plantules) accomplished in 'Lagoão do Ouro' stream, Santa Maria-RS state.

\begin{tabular}{|c|c|c|c|c|c|c|c|c|}
\hline Família/Nome Científico & Arbó & R.Nat & Plânt. & $\mathrm{N}$ & FA & FR & DA & DR \\
\hline Anacardiaceae & & & & & & & & \\
\hline Schinus terebinthifolius Raddi & 9 & 22 & 33 & 64 & 50 & 3,14 & 177,78 & 1,31 \\
\hline
\end{tabular}


TABELA 1: Continuação...

TABLE 1: Continued...

\begin{tabular}{|c|c|c|c|c|c|c|c|c|}
\hline Família/Nome Científico & Arbó & R.Nat & Plânt. & $\mathrm{N}$ & FA & FR & DA & DR \\
\hline Schinus polygamus (Cav.) Cabrera & 3 & - & - & 3 & 16,67 & 1,05 & 8,33 & 0,06 \\
\hline \multicolumn{9}{|l|}{ Annonaceae } \\
\hline Annona neosalicifolia H. Rainer & 14 & 10 & 2 & 26 & 8,33 & 0,52 & 72,22 & 0,53 \\
\hline \multicolumn{9}{|l|}{ Aquifoliaceae } \\
\hline Ilex dumosa Reissek & 1 & - & - & 1 & 8,33 & 0,52 & 2,78 & 0,02 \\
\hline \multicolumn{9}{|l|}{ Arecaceae } \\
\hline \multicolumn{9}{|l|}{ Asteraceae } \\
\hline $\begin{array}{c}\text { Baccharis dracunculifolia DC. } \\
\text { Bignoniaceae }\end{array}$ & 22 & 39 & 33 & 94 & 33,33 & 2,09 & 261,11 & 1,93 \\
\hline Tecoma stans (L.) Juss. ex Kunth & 1 & 2 & - & 3 & 16,67 & 1,05 & 8,33 & 0,06 \\
\hline \multicolumn{9}{|l|}{ Escalloniaceae } \\
\hline Escallonia bifida Link \& Otto & 1 & 3 & - & 4 & 8,33 & 0,52 & 11,11 & 0,08 \\
\hline \multicolumn{9}{|l|}{ Euphorbiaceae } \\
\hline Sebastiania commersoniana (Baill.) L.B.Sm. \& Downs & 5 & 13 & 1 & 19 & 16,67 & 1,05 & 52,78 & 0,39 \\
\hline Actinostemon concolor (Spreng.) Müll.Arg. & - & 3 & - & 3 & 16,67 & 1,05 & 8,33 & 0,06 \\
\hline Ricinus communis $\mathrm{L}$. & 5 & 2 & 1 & 8 & 25 & 1,57 & 22,22 & 0,16 \\
\hline Sapium glandulosum (L.) Morong & 17 & 17 & 1 & 35 & 33,33 & 2,09 & 97,22 & 0,72 \\
\hline \multicolumn{9}{|l|}{ Fabaceae } \\
\hline Albizia niopoides (Spruce ex Benth.) Burkart & - & 1 & - & 1 & 8,33 & 0,52 & 2,78 & 0,02 \\
\hline Parapiptadenia rigida (Benth.) Brenan & 1 & - & - & 1 & 8,33 & 0,52 & 2,78 & 0,02 \\
\hline Peltophorum dubium (Spreng.) Taub. & 1 & 1 & - & 2 & 16,67 & 1,05 & 5,56 & 0,04 \\
\hline Senna multijuga (Rich.) H.S. Irwin \& Barneby & 8 & 6 & 6 & 20 & 16,67 & 1,05 & 55,56 & 0,41 \\
\hline Mimosa bimucronata (DC.) Kuntze & 68 & 8 & - & 76 & 25 & 1,57 & 211,11 & 1,56 \\
\hline \multicolumn{9}{|l|}{ Lamiaceae } \\
\hline Vitex megapotamica (Spreng.) Moldenke & - & - & 1 & 1 & 8,33 & 0,52 & 2,78 & 0,02 \\
\hline \multicolumn{9}{|l|}{ Lauraceae } \\
\hline Ocotea acutifolia (Nees) Mez & 4 & - & 3 & 7 & 25 & 1,57 & 19,44 & 0,14 \\
\hline Nectandra lanceolata Nees & - & 13 & 17 & 30 & 16,67 & 1,05 & 83,33 & 0,62 \\
\hline Cinnamomum zeylanicum Blume & 1 & 12 & 20 & 33 & 16,67 & 1,05 & 91,67 & 0,68 \\
\hline Ocotea puberula (Rich.) Nees & 17 & 34 & 33 & 84 & 41,67 & 2,62 & 233,33 & 1,72 \\
\hline Ocotea pulchella (Nees) Mez & 2 & 5 & 2 & 9 & 8,33 & 0,52 & 25 & 0,18 \\
\hline Nectandra megapotamica (Spreng.) Mez & - & 8 & 15 & 23 & 16,67 & 1,05 & 63,89 & 0,47 \\
\hline \multicolumn{9}{|l|}{ Melastomataceae } \\
\hline Miconia cinerascens Miq. & 4 & 2 & - & 6 & 8,33 & 0,52 & 16,67 & 0,12 \\
\hline Leandra sp. & - & 324 & 409 & 733 & 25 & 1,57 & 2036,11 & 15,03 \\
\hline
\end{tabular}


TABELA 1: Continuação...

TABLE 1: Continued...

\begin{tabular}{|c|c|c|c|c|c|c|c|c|}
\hline Família/Nome Científico & Arbó & R.Nat & Plânt. & $\mathrm{N}$ & FA & FR & DA & DR \\
\hline \multicolumn{9}{|l|}{ Meliaceae } \\
\hline Trichilia elegans A.Juss. & 3 & 13 & 3 & 19 & 8,33 & 0,52 & 52,78 & 0,39 \\
\hline Cedrela fissilis Vell. & - & 1 & - & 1 & 8,33 & 0,52 & 2,78 & 0,02 \\
\hline $\begin{array}{c}\text { Melia azedarach } \mathrm{L} \text {. } \\
\text { Moraceae }\end{array}$ & 1 & - & - & 1 & 8,33 & 0,52 & 2,78 & 0,02 \\
\hline \multicolumn{9}{|l|}{ Primulaceae } \\
\hline \multicolumn{9}{|l|}{ Myrtaceae } \\
\hline Psidium cattleianum Sabine & 6 & 33 & 52 & 91 & 25 & 1,57 & 252,78 & 1,87 \\
\hline Eucalyptus sp. & 20 & 3 & 1 & 24 & 16,67 & 1,05 & 66,67 & 0,49 \\
\hline Psidium guajava $\mathrm{L}$. & 6 & 14 & 12 & 32 & 66,67 & 4,19 & 88,89 & 0,66 \\
\hline Campomanesia xanthocarpa O. Berg & - & 1 & - & 1 & 8,33 & 0,52 & 2,78 & 0,02 \\
\hline $\begin{array}{c}\text { Eugenia uniflora } \mathrm{L} . \\
\text { Oleaceae }\end{array}$ & 84 & 363 & 241 & 688 & 83,33 & 5,24 & 1911,11 & 14,11 \\
\hline $\begin{array}{c}\text { Ligustrum lucidum W.T. Aiton } \\
\text { Phytolaccaceae }\end{array}$ & \multicolumn{7}{|c|}{ Phytolaccaceae } & 2,26 \\
\hline $\begin{array}{l}\text { Phytolacca dioica } \mathrm{L} . \\
\text { Pinaceae }\end{array}$ & \multicolumn{7}{|c|}{ Pinaceae } & 0,08 \\
\hline \multicolumn{9}{|l|}{ Pittosporaceae } \\
\hline \multicolumn{9}{|l|}{ Podocarpaceae } \\
\hline $\begin{array}{l}\text { Podocarpus lambertii Klotzsch ex Endl. } \\
\text { Rhamnaceae }\end{array}$ & 3 & 3 & 66 & 72 & 16,67 & 1,05 & 200 & 1,48 \\
\hline Scutia buxifolia Reissek & 2 & 3 & 1 & 6 & 8,33 & 0,52 & 16,67 & 0,12 \\
\hline \multicolumn{9}{|l|}{ Rosaceae } \\
\hline Eriobotrya japonica (Thunb.) Lindl. & - & - & 4 & 4 & 16,67 & 1,05 & 11,11 & 0,08 \\
\hline \multicolumn{9}{|l|}{ Rubiaceae } \\
\hline \multicolumn{9}{|l|}{ Rutaceae } \\
\hline Citrus sp. 1 & - & 6 & 4 & 10 & 25 & 1,57 & 27,78 & 0,21 \\
\hline Helietta apiculata Benth. & 2 & 9 & 1 & 12 & 16,67 & 1,05 & 33,33 & 0,25 \\
\hline Citrus sp. 2 & 5 & 6 & - & 11 & 33,33 & 2,09 & 30,56 & 0,23 \\
\hline \multicolumn{9}{|l|}{ Salicaceae } \\
\hline Casearia sylvestris $\mathrm{Sw}$. & 131 & 98 & 30 & 259 & 50 & 3,14 & 719,44 & 5,31 \\
\hline
\end{tabular}


TABELA 1: Continuação...

TABLE 1: Continued..

\begin{tabular}{|c|c|c|c|c|c|c|c|c|}
\hline Família/Nome Científico & Arbó & R.Nat & Plânt. & $\mathrm{N}$ & FA & FR & DA & DR \\
\hline Salix humboldtiana Willd. & 1 & - & - & 1 & 8,33 & 0,52 & 2,78 & 0,02 \\
\hline Xylosma tweediana (Clos) Eichler & 1 & - & 4 & 5 & 16,67 & 1,05 & 13,89 & 0,1 \\
\hline \multicolumn{9}{|l|}{ Sapindaceae } \\
\hline Matayba elaeagnoides Radlk. & 13 & 25 & 10 & 48 & 41,67 & 2,62 & 133,33 & 0,98 \\
\hline Cupania vernalis Cambess. & 6 & 28 & 58 & 92 & 50 & 3,14 & 255,56 & 1,89 \\
\hline $\begin{array}{l}\text { Allophylus edulis (A.St.-Hil., Cambess. \& A. Juss.) Radlk } \\
\text { Sapotaceae }\end{array}$ & 28 & 52 & 50 & 130 & 66,67 & 4,19 & 361,11 & 2,67 \\
\hline $\begin{array}{c}\text { Chrysophyllum gonocarpum (Mart. \& Eichler) Engl. } \\
\text { Solanaceae }\end{array}$ & - & 2 & 4 & 6 & 8,33 & 0,52 & 16,67 & 0,12 \\
\hline Cestrum strigilatum Ruiz \& Pav. & 28 & 90 & 49 & 167 & 58,33 & 3,66 & 463,89 & 3,42 \\
\hline \multicolumn{9}{|l|}{ Symplocaceae } \\
\hline Symplocos uniflora (Pohl) Benth. & 2 & 4 & 4 & 10 & 16,67 & 1,05 & 27,78 & 0,21 \\
\hline $\begin{array}{l}\text { Symplocos tetrandra (Mart.) Miq. } \\
\text { Thymelaeaceae }\end{array}$ & 8 & 3 & 1 & 12 & 8,33 & 0,52 & 33,33 & 0,25 \\
\hline Daphnopsis racemosa Griseb. & 7 & 17 & 13 & 37 & 16,67 & 1,05 & 102,78 & 0,76 \\
\hline
\end{tabular}

Em que: Arbó (estrato arbóreo); R.Nat. (estrato regeneração natural); Plânt. (estrato plântulas); N (número de indivíduos); FA (frequência absoluta em \%); FR (frequência relativa em \%); DA (densidade absoluta em número de indivíduos ha ${ }^{-1}$ ); DR (densidade relativa em \%).

As famílias com maior número de espécies foram Fabaceae com seis $(9,09 \%)$, Euphorbiaceae, Lauraceae, e Myrtaceae com cinco (7,58\%) espécies cada uma, Rutaceae com quatro (6,06\%) e Meliaceae, Salicaceae e Sapindaceae com três $(4,54 \%)$ cada uma. Resultado semelhante foi encontrado por Scipioni et al. (2011), em uma floresta estacional no norte do estado do RS, por Andrzejewski (2016), em floresta estacional decidual ripária no noroeste do RS e por Velazco et al. (2015), em Floresta Estacional Semidecidual ripária na Argentina, na qual as famílias Fabaceae e Myrtaceae foram as mais representativas em termos de espécie.

Os resultados observados por Longhi, Capra e Minello (2002), em um estudo fitossociológico de um trecho da mata ciliar do arroio Vacacaí-mirim em Santa Maria-RS, assemelham-se aos deste trabalho, pois as famílias Myrtaceae, Fabaceae, Euphorbiaceae, Lauraceae e Sapindaceae foram as mais ricas em espécies. Os mesmos autores salientam que a família Myrtaceae ficou em segundo lugar em termos de densidade, embora tenha apresentado maior número de espécies. Os dados de frequência e densidade também se assemelham na maioria das espécies do presente estudo.

As famílias que apresentaram maior número de indivíduos foram Rosaceae com 1.320 (27,06\%), Myrtaceae com 836 (17,14\%), Melastomataceae com 739 (15,15\%), Salicaceae e Sapindaceae com 270 indivíduos cada (5,54\%), Solanaceae com 186 (3,81\%), Lauraceae com 181 (3,71\%) e Rutaceae com 111 $(2,28 \%)$. Essas famílias juntas representam $80,23 \%$ do número total de indivíduos amostrados e estão sempre presentes na maioria dos ecossistemas ripários do Rio Grande do Sul com uma boa representatividade de espécies e abundância de indivíduos.

Os resultados observados neste trabalho, com relação às famílias mais representativas, exceto Melastomataceae e Solanaceae, confirmam a literatura (JARENKOW; WEACHTER, 2001; LONGHI et al., 2002; ARAÚJO et al., 2004; SCIPIONI et al., 2011; ANDRZEJEWSKI, 2016) para o mesmo tipo florestal. A exceção das famílias Melastomataceae e Solanaceae, presentes com grande número de indivíduos, deve-se ao fato do presente trabalho ter incluído no levantamento florístico as espécies chamadas de capoeirão, 
ou seja, aquelas típicas dos estágios iniciais da sucessão florestal em um processo de recuperação pós degradação.

Foi observada a presença de várias espécies exóticas, sendo as mais significantes Pinus elliottii, Eucalyptus sp., Ligustrum lucidum, Hovenia dulcis, Morus nigra, Citrus sp., Eriobotrya japonica e Melia azedarach. Andrzejewski (2016) também encontrou espécies dos gêneros Citrus e Morus. Segundo Scipioni et al. (2009), a presença de elementos exóticos é indicativo de alterações antrópicas. Para Ziller (2001), o processo de invasão de um ecossistema por uma planta exótica, ou a contaminação biológica, ocorre quando qualquer espécie não natural é introduzida nele e se naturaliza, passando a se dispersar e a alterar esse ecossistema. A invasão por plantas exóticas afeta o funcionamento natural do ecossistema e tira espaço das plantas nativas.

Parapiptadenia rigida, Schinus polygamus, Ilex dumosa, Salyx humboldtiana e Enterolobium contortisiliquum foram encontradas apenas no estrato arbóreo e com poucos exemplares, mostrando que estas espécies estão tendo dificuldade de se regenerarem. Chrysophyllum gonocarpum, Albizia niopoides, Nectandra lanceolata, Nectandra megapotamica, Cedrela fissilis, Campomanesia xanthocarpa, Gymnanthes concolor e Vitex megapotamica foram encontradas somente nos estratos inferiores. Exemplares adultos destas espécies podem estar além da mata ciliar e suas sementes terem sido transportadas até o local e/ou os exemplares do estrato arbóreo terem sido retirados anteriormente ao levantamento florístico.

A diversidade florística, estimada pelo índice de Shannon foi de 2,77 nats/ind, estando assim coerente com o exposto por Vaccaro (1997), que descreveu que o valor desse índice normalmente fica entre 1,5 e 3,5, para a vegetação da Floresta Estacional Decidual. Para o mesmo tipo florestal, Andrzejewski (2016) obteve índice de Shannon de 2,99 e 3,10, em dois fragmentos ciliares avaliados no noroeste do RS. Valores semelhantes foram encontrados nos trabalhos de Ávila et al. (2011) e Hüller et al. (2011) em florestas ripárias do rio Ijuí (3,02 e 3,07, respectivamente). A floresta do presente estudo apresenta diversidade semelhante à pesquisa de Budke et al. (2004), em floresta ciliar em Santa Maria-RS (2,73 nats/ind), e maior ao estudo de Kipper et al. (2010), realizado em mata ciliar de Floresta Estacional Semidecidual, no Paraná $(2,05)$.

As espécies Eugenia uniflora, Psidium guajava, Allophylus edulis, Cestrum strigilatum, Prunus myrtifolia, Zanthoxylum rhoifolium, Schinus terebinthifolius, Cupania vernalis, e Casearia sylvestris são as que apresentaram maior frequência, ou seja, as que estavam presentes em maior número de parcelas e, portanto, com distribuição mais ampla, sendo Eugenia uniflora a espécie de maior frequência $(83,33 \%)$. Estas espécies são as mais comumente encontradas em ecossistemas ciliares e são as de maior importância ecológica neste tipo de ecossistema. Além disso, todas elas ocorreram nos três estratos amostrados, mostrando possuir potencial de regeneração natural.

Araújo et al. (2004) salientam a frequência com que a espécie Eugenia uniflora é encontrada na vegetação ciliar no sul do Brasil. Reitz, Klein e Reis (1983) descrevem a espécie como própria para reflorestamento de margens de rios, em razão de suas raízes pivotantes, que atuam contra a erosão, além de seus frutos serem atrativo para a fauna dispersora, o que facilita a regeneração natural.

As espécies que apresentaram maior densidade foram Prunus myrtifolia com 3.655,56 indivíduos $\mathrm{ha}^{-1}$, a que representa uma densidade de $26,98 \%$ do total de indivíduos observados na mata ciliar da Sanga Lagoão do Ouro, seguido pela Eugenia uniflora com 1.911,11 indivíduos ha ${ }^{-1}(14,11 \%$ de densidade relativa), Casearia sylvestris, Cestrum strigilatum, Allophylus edulis, Cupania vernalis entre outras. As espécies com maior densidade estão, também, entre as que apresentam maior frequência.

Para Alvarenga (2004), a composição florística das matas ciliares depende de vários fatores, dentre os quais a proximidade de outras formações e as características do curso d'água, tais como: topografia das margens, regime de inundação, processos de sedimentação, flutuação do lençol freático, tipos de solo e condições mesoclimáticas. De acordo com Martins (2001), as matas ciliares apresentam uma heterogeneidade florística elevada por ocuparem diferentes ambientes ao longo das margens dos rios. A grande variação de fatores ecológicos nas margens dos cursos d'água resulta em uma vegetação arbustiva e arbórea adaptada a tais condições.

Avaliar a composição florística e o número de indivíduos de cada espécie presente, bem como a presença e número de espécies exóticas, permite inferir sobre a degradação de um ecossistema ciliar. Pelos dados obtidos no levantamento florístico, observa-se que há perturbação na composição ciliar ocasionada, provavelmente, pela ação antrópica, através do conflito de uso das áreas que margeiam a Sanga Lagoão do 
Ouro. Entre estes conflitos de uso destacam-se a urbanização, a agricultura e a pecuária. Como os ecossistemas ciliares são áreas de preservação permanente, nenhum dos usos listados deve ser dado a estas áreas, pois interferem na dinâmica e função das mesmas, podendo levar a sua degradação, fazendo-se necessárias medidas mitigadoras e/ou de recuperação.

Para o restabelecimento da vegetação deve-se considerar a composição florística. De acordo com Van Den Berg e Oliveira Filho (2000), Scipioni et al. (2009), Callegaro et al. (2012a) e Figueiredo (2014), para embasar qualquer iniciativa de proteger, enriquecer ou recuperar a vegetação florestal é necessário realizar estudos sobre a composição florística e ecológica das comunidades arbóreas remanescentes em cada região ou área específica.

De acordo com Werneck et al. (2000) e Alvarenga (2004), o conhecimento da composição florística e da ecologia das comunidades vegetais é fundamental para o desenvolvimento de modelos de recuperação de áreas degradadas, pois facilita a escolha das espécies a serem usadas na revegetação. Fonseca et al. (2017) observaram que a riqueza e a densidade de espécies plantadas afetam diretamente a riqueza das espécies em regeneração natural, o que reforça a importância dos plantios com uma certa diversidade de espécies nativas para o processo de retomada da trajetória sucessional em áreas de restauração florestal.

Conforme Carvalho (2000), para uma recuperação efetiva da mata ciliar deve-se observar características ecológicas como: escolher preferencialmente as espécies vegetais regionais e que ocorram em locais com as mesmas características da área a ser recuperada; levar em consideração os processos de sucessão natural; avaliar o banco de sementes do solo (principalmente para as espécies pioneiras); avaliar espécies que não permitam ou dificultam o estabelecimento de processo sucessional, etc.

Segundo Martins (2001), o estudo da regeneração natural das florestas ciliares é de grande importância devido ao papel que estes ecossistemas desempenham para as comunidades, direta ou indiretamente, a eles vinculados. Este autor também evidencia que a regeneração natural é essencial, para assegurar que as matas ciliares desempenhem suas funções, pois é a reposição natural das espécies e o surgimento de outras, conforme o nível de desenvolvimento dos estágios sucessionais, que vão garantir o equilíbrio e a perpetuação dos ecossistemas. Segundo o mesmo autor, a quantificação da regeneração natural, quando associada com a classificação sucessional, compõe um indicador extremamente útil das condições de recuperação e de sustentabilidade da floresta ciliar. Salienta ainda que, na regeneração natural, no interior da floresta, espécies típicas dos estágios iniciais de sucessão (pioneiras e secundárias iniciais) predominam em número de espécies e/ou de indivíduos, como é o caso do presente estudo, tem-se um indicativo de que a sucessão está muito lenta na área e que as espécies tardias não estão conseguindo chegar até o local ou, embora estejam chegando, por algum motivo, não estão conseguindo se estabelecer. Neste caso é necessário algum tipo de intervenção antrópica.

\section{CONCLUSÕES}

O levantamento florístico mostrou haver degradação da mata ciliar, evidenciada pela má distribuição das espécies nos diferentes estratos e pela grande presença de espécies exóticas.

As espécies Eugenia uniflora, Allophylus edulis, Psidium guajava, Cestrum strigilatum, Prunus myrtifolia, Zanthoxylum rhoifolium, Casearia sylvestris, Cupania vernalis e Schinus terebinthifolius estão bem representadas na área e contribuem para a manutenção das margens da Sanga estudada.

Há necessidade de restauração das margens da Sanga, com plantios de espécies adaptadas as condições ambientais do local, de preferência com as espécies tardias não encontradas no levantamento.

\section{REFERÊNCIAS}

ALVARENGA, A. P. Avaliação inicial da recuperação de matas ciliares em nascentes. 2004. 175 f. Dissertação (Mestrado em Engenharia Florestal) - Universidade Federal de Lavras, Lavras, 2004.

ANDRZEJEWSKI, C. Estrutura e florística de duas florestas estacionais deciduais ripárias, no Noroeste do Rio Grande do Sul, Brasil. 2016. 86 f. Dissertação (Mestrado em Engenharia Florestal) Universidade Federal de Santa Maria, Santa Maria, 2016. 
ANGIOSPERM PHYLOGENY GROUP. An update of the Angiosperm Phylogeny Group classification for the orders and families of flowering plants: APG IV. Botanical Journal of the Linnean Society, Lodon, v. 181, p. 1-20, 2016.

ARAÚJO, M. M. et al. Aspectos fitossociológicos de três sub-formações florísticas encontradas em fragmento de floresta estacional decidual ripária, Cachoeira do Sul, RS, Brasil. In: SIMPÓSIO LATINO-AMERICANO SOBRE MANEJO FLORESTAL, 3., 2004, Santa Maria. Anais... Santa Maria: UFSM; CCR; PPGEF, 2004. p. 339-344.

ÁVILA, A. L. et al. Caracterização da vegetação e espécies para recuperação de mata ciliar, Ijuí, RS. Ciência Florestal, Santa Maria, v. 21, n. 2, p. 251-260, 2011.

BUDKE, J. C. et al. Florística e fitossociologia do componente arbóreo de uma floresta ribeirinha, arroio Passo das Tropas, Santa Maria, RS, Brasil. Acta Botanica Brasilica, Belo Horizonte, v. 18, n. 3, p. 581-589, 2004.

BRASIL. Lei $\mathbf{n}^{\mathbf{0}}$ 12.651, de 25 de maio de 2012. Dispõem sobre a proteção da vegetação nativa. Disponível em: <http://www.planalto.gov.br/ccivil_03/_ato2011-2014/2012/lei/112651.htm>. Acesso em: mar. 2017.

BREN, L. J. Riparian zone, stream, and floodplain issues: a review. Journal of Hydrology, Amsterdam, v. 150, n. $2 / 4$, p. $277-229,1993$.

CALLEGARO, R. M. et al. Estrutura do componente arbóreo de uma floresta estacional decidual ripária em Jaguari, RS. Ciência Rural, Santa Maria, v. 42, n. 2, p. 305-311, fev. 2012a.

CALLEGARO, R. M. et al. Regeneração natural avançada de um fragmento de mata ciliar em Jaguari, RS, Brasil. Agrária, Recife, v. 7, n. 2, p. 315-321, 2012b.

CARPANEZZI, A. A. Benefícios indiretos da floresta. In: GALVÃO, A. P. M. (Org.). Reflorestamento de propriedades rurais para fins produtivos e ambientais: um guia para ações municipais e regionais. Colombo: Embrapa Florestas, 2000. p. 19-55.

CARVALHO, P. E. R. Técnicas de recuperação e manejo de áreas degradadas. In: GALVÃO, A. P. M. (Org.). Reflorestamento de propriedades rurais para fins produtivos e ambientais: um guia para ações municipais e regionais. Colombo: Embrapa Florestas, 2000. p. 251-268.

COGO, C. M.; ELTZ, F. L. F.; CASSOL, E. A. Erosividade das chuvas em Santa Maria, RS, determinada pelo índice $\mathrm{EI}_{30}$. Revista Brasileira de Agrometeorologia, Santa Maria, v. 14, n. 3, p. 1-11, 2006.

FIGUEIREDO, M. C. S. Florística de mata ciliar em São Martinho da Serra, RS, Brasil. 2014. 64 f. Dissertação (Mestrado em Agrobiologia) - Universidade Federal de Santa Maria, Santa Maria, 2014. FONSECA, D. A. et al. Avaliação da regeneração natural em área de restauração ecológica e mata ciliar de referência. Ciência Florestal, Santa Maria, v. 27, n. 2, p. 521-534, 2017.

HÜLLER, A. et al. Estrutura fitossociológica da vegetação arbórea do Parque Natural Municipal de Santo Ângelo, Santo Ângelo, RS. Ciência Florestal, Santa Maria, v. 21, n. 4, p. 629-639, 2011.

JARENKOW, J. A.; WAECHTER, J. L. Composição, estrutura e relações florísticas do componente arbóreo de uma floresta estacional no Rio Grande do Sul, Brasil. Revista Brasileira de Botânica, São Paulo, v. 24, n. 3, p. 263-272, 2001.

KIPPER, J. et al. Levantamento florístico de um componente arbóreo de mata ciliar do rio Paraná, Marechal Cândido Rondon, PR. Scientia Agraria Paranaensis, Marechal Cândido Rondon, v. 9, n. 1, p. 82-92, 2010. LONGHI, S. J.; CAPRA, A.; MINELLO, A. L. Estudo fitossociológico de um trecho de mata ciliar do rio Vacacaí-mirim em Santa Maria-RS. In: CONGRESSO FLORESTAL ESTADUAL, 8., 2002, Nova Prata. Anais... Santa Maria: UFSM, 2002. CD-ROM.

LONGHI, S. J. et al. Aspectos da composição florística e fitossociologia de um fragmento de floresta estacional decidual no município de Santa Maria-RS. In: CICLO DE ATUALIZAÇ̃̃O FLORESTAL DO CONESUL, 2., 2002, Santa Maria. Anais... Santa Maria: UFSM, 2002. CD-ROM.

LONGHI, S. J. et al. Aspectos fitossociológicos de fragmento de Floresta Estacional Decidual, Santa Maria, RS. Ciência Florestal, Santa Maria, v. 10, n. 2, p. 59-74, 2000.

MARTINS, F. R. Estrutura de uma floresta mesófila. Campinas: UNICAMP, 1991. 246 p.

MARTINS, S. V. Recuperação de matas ciliares. Viçosa, MG: Aprenda Fácil, 2001. 143 p.

MORENO, J. A. Clima do Rio Grande do Sul. Porto Alegre: Secretaria da Agricultura, 1961. 41 p.

PEDRON, F. A. et al. Utilização do sistema de avaliação do potencial de uso urbano das terras ao diagnóstico ambiental do município de Santa Maria - RS. Ciência Rural, Santa Maria, v. 36, n. 2, p. 468-477, 2006. 
RACHWAL, M. F. G.; CAMATI, A. R. Diagnóstico expedido sobre ocupação e conservação dos ambientes ciliares do município de Pinhais. Colombo: Embrapa Florestas, 2001. 43 p. (Documentos, 64). REITZ, P.; KLEIN, R. M.; REIS, A. Projeto madeira do Rio Grande do Sul. Itajaí: Herbário Barbosa Rodrigues, 1983.525 p.

RIO GRANDE DO SUL. Secretaria Estadual do Meio Ambiente. Inventário florestal contínuo do Rio Grande do Sul. 2002. Disponível em: <www.ufsm.br/ifcrs/>. Acesso em: abr. 2010.

SHIMIZU, J. Y. Estratégia complementar para conservação de espécies florestais nativas: resgate e conservação de ecótipos ameaçados. Pesquisa Florestal Brasileira, Colombo, n. 54, p. 7-35, 2007.

SCIPIONI, M. C. et al. Fitossociologia em fragmento florestal no noroeste do estado do Rio Grande do Sul. Ciência Florestal, Santa Maria, v. 21, n. 3, p. 409-419, 2011.

SCIPIONI, M. C. et al. Regeneração natural de um fragmento da floresta estacional decidual na Reserva Biológica do Ibicuí-Mirim (RS). Floresta, Curitiba, v. 39, n. 3, p. 675-690, jul./set. 2009.

SPIAZZI, C. F. T. Análise dos aspectos populacionais, infra-estrutura e equipamentos urbanos das Vilas Soares do Canto, Jardim e Aparício de Moraes no Bairro Camobi, Santa Maria - RS. 2002. 67 f. Monografia (Bacharelado em Geografia) - Universidade Federal de Santa Maria, Santa Maria, 2002. STRECK, E. V. et al. Solos do Rio Grande do Sul. Porto Alegre: Editora da UFRGS, 2002. 107 p. VACCARO, S. Caracterização fitossociológica de três fases sucessionais de uma Floresta Estacional Decidual, no município de Santa Tereza, RS. 1997. 92 f. Dissertação (Mestrado em Engenharia Florestal) - Universidade Federal de Santa Maria, Santa Maria, 1997.

VAN DEN BERG, E.; OLIVEIRA FILHO, A. T. Composição florística e estrutura fitossociológica de uma floresta ripária em Itutinga, MG, e comparação com outras áreas. Revista Brasileira de Botânica, São Paulo, v. 23, n. 3, p. 231-253, 2000.

VELAZCO, S. J. E. et al. Florística e Fitossociologia de uma Floresta Estacional Semidecidual, Reserva Privada Osununú-Misiones, Argentina. Floresta e Ambiente, Seropédica, v. 22, n. 1, p. 1-12, 2015.

VOGEL, H. F.; ZAWADZKI, C. H.; METRI, R. Florestas ripárias: importância e principais ameaças. SaBios: Revista Brasileira de Saúde e Biologia, Campo Mourão, v. 4, n. 1, p. 24-30, 2009.

WERNECK, M. S. et al. Florística e estrutura de três trechos de uma floresta semidecídua na estação ecológica do Tripuí, Ouro Preto, MG. Revista Brasileira de Botânica, São Paulo, v. 23, n. 1, p. 97-106, 2000. ZILLER, S. R. Plantas exóticas invasoras: a ameaça da contaminação biológica. Ciência Hoje, Rio de Janeiro, v. 30, n. 178, p. 77-79, 2001. 